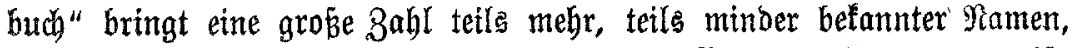
barunter auch jenen Sagenbed's, mit befien Bilb bas Buch geziert ift.

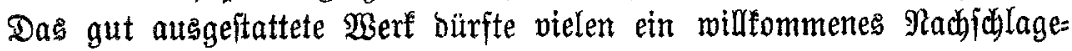
bud jein.

$r$.

\title{
IV. Matizen.
}

\section{Tedhrifde Godifinule Karlsruhe.}

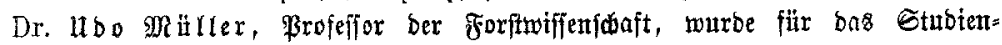

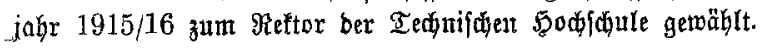

\section{Todesnachriht.}

Der ehemaltge langiährige Borftanb ber Sgl. Bayerifaen Staatsforftorwaltung Mintiterialdireftor Seinrid Mitter von Suber if am 24. Surni in Münden ge= forben unb am 26. Sunt auf Dem neuen nörbliden Friebbofe bafelbft beftattet borbent.

Die "Bryerifde Stantzetung" wibmet Dem Berftorbenent in ihrer 9 Rr. 147 vom

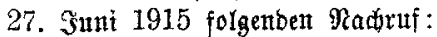

Der frübere langjährige Shef ber bnyerifoden Forftberwaltung, Dinifterinlbireftor

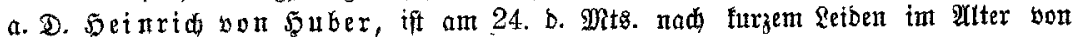

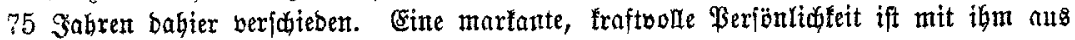

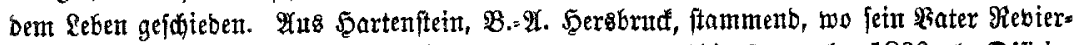
förfter war, trat ber Berftorbente 1863 in ben Staataforftbienft, madite 1866 als Dif̈zier ben Frieg mit, murbe 1871 Forftant8affiftent in Berditesgaben unb in gletcher Eigen=

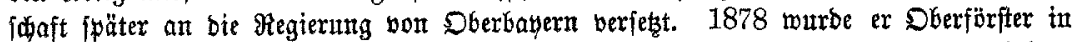

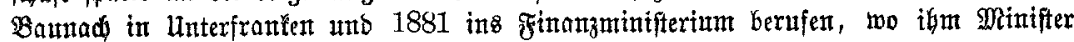
Frhr. bon Riebel bie Artarbeitung ber 1885 in Rebent getretenen Forftorganifation ïbertrug, bie im ganzen bas 2 sert 5 aber's war. 1883 rïfte ax zum Forftmeifter, 1885 zum Forftrat, 1887 zum Dberforftrat, 1897 als Nadfolger von Gang of ers zun Minifterialrat und am 1. Sanuar 1909 zum Minifterialdirettor vor. Mm 1. Miärz 1909 trat er in ben Rubeftanb. OUts Miniftertalreferent hatte ber Berforbene bas

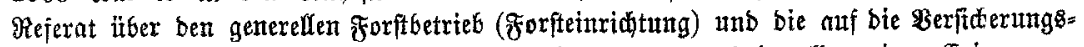
gefebgefung bezägliden Mngelegenbeiten. Befannt anb nod it alfgemeiner Erinnerung

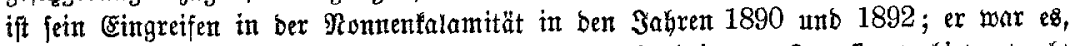

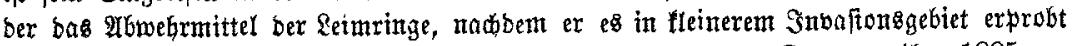
batte, nud allgemein empfahl mb zur Durdifibrung bracte. Das bon ibm 1885 ges

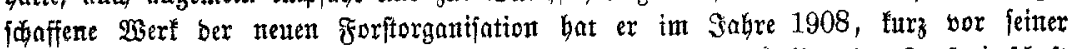

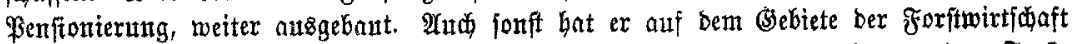
eine überaut anregente Tätiglett entfaltet, ingbelonbere bat ex fid um bas forft= einridutungewejen verbtent gemadht. Seine hohen Berbienfte haben in Der Berleibung zablreidjer boher Srben fiditbarent Ausbrut gefumben; fo twurbe ibm beret 1895 bas

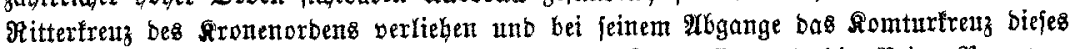

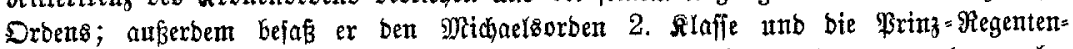
Mebaille in Silber. Der Berftorbene, ber fit wegen feine offenen, geraben, aber

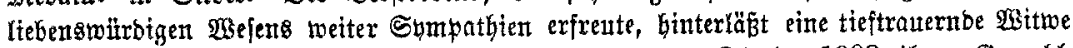
unb zwet berheiratete Iöduter, bon bemen bie ältefte im Oftober 1908 ifren (semabl,

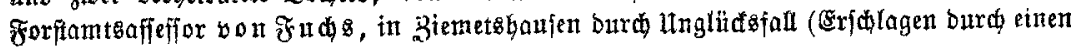
$\mathfrak{B a u m )}$ verloren bat. 